\title{
Profile Analysis of Sexual Assault Experiences among Adult Women and Their Implications for Mental Health
}

\author{
Kihyun $\mathrm{Kim}^{1}$, Bee $\mathrm{Ryou}^{2}{ }^{凶}$, Jihyeon $\mathrm{Choi}^{3}$, and Jae-Won $\mathrm{Kim}^{4}$ \\ ${ }^{1}$ Department of Social Welfare, College of Social Sciences, Sungkyunkwan University, Seoul, Republic of Korea \\ ${ }^{2}$ Policy Research Institute, Incheon Metropolitan City Public Agency for Social Service, Incheon, Republic of Korea \\ ${ }^{3}$ Co-Research Coop, Seoul, Republic of Korea \\ ${ }^{4}$ Division of Child and Adolescent Psychiatry, Department of Psychiatry \& Behavioral Sciences, Seoul National University College of Medicine, \\ Seoul, Republic of Korea
}

\begin{abstract}
Objective Extant studies indicate that just one characteristic of sexual assault cannot properly represent the whole experience of sexual assault and, especially, the severity of sexual assault. This study aimed to understand the totality of sexual assault experiences and elucidate subtypes of sexual assault victims based on the detailed characteristics of their sexual assault experiences and those relationships with mental health.
\end{abstract}

Methods A total of 255 adult sexual violence victims who used intervention services and a comparison group were included. Information on their sexual assault experiences was gleaned from case records data.

Results The following four distinctive profile groups were identified: “Sexual Touching” (19.6\%), "Rape/Social Relation” (30.4\%), "Intimate Partner Violence (IPV)" (18.8\%), and "Rape/Stranger" (31.3\%). The subgroups differed in terms of secondary victimization and adverse childhood experiences. The Rape/Social Relation and IPV subgroups most frequently experienced secondary victimization and childhood adversity. The four profile subgroups demonstrated different relationships with mental health outcomes, with a complicated pattern. The Rap/Social Relation and IPV subgroups scored higher on mental health problem screening measures compared to other groups. However, a considerable proportion of victims in the Sexual Touching subgroup also reported suicidal behaviors and self-injury. Conclusion Based on the results, theoretical and clinical implications were discussed.

Psychiatry Investig 2021;18(4):312-323

Key Words Psychosocial, Trauma related disorder.

\section{INTRODUCTION}

As many as one in five females in the United States has experienced completed or attempted rape in their lifetime and, when the definition of sexual assault is broadened to include unwanted sexual contact, more than $40 \%$ report having been sexually assaulted. ${ }^{1}$ In South Korea, $21.3 \%$ of adult females have reported experiencing rape, attempted rape, or unwanted sexual touching. ${ }^{2}$ The Proper intervention and treatment of victims of sexual assault are important public health issues. This is because victims of sexual assault experience not only

Received: April 25, 2020 Revised: June 13, 2020

Accepted: January 10, 2021

$\triangle$ Correspondence: Bee Ryou, PhD

Policy Research Institute, Incheon Metropolitan City Public Agency for Social Service, 229 Gyeongin-ro, Michuhol-gu, Incheon 22106, Republic of Korea Tel: +82-32-721-5977, Fax: +82-32-721-6990, E-mail: ub@incheon.pass.or.kr

(c) This is an Open Access article distributed under the terms of the Creative Commons Attribution Non-Commercial License (https://creativecommons.org/licenses/bync/4.0) which permits unrestricted non-commercial use, distribution, and reproduction in any medium, provided the original work is properly cited. significant mental health and psychological problem, but also secondary victimization after an assault. Therefore, intervention and treatment of these people requires a holistic approach that encompasses psychosocial environment and its evidence. $^{3-11}$

Characteristics of sexual assault that affect the mental health of the survivors ${ }^{6,12}$ include assault type and severity, relationship with the perpetrator, frequency, age of onset, degree of physical violence involved, and the role of drugs or alcohol. However, previous studies of the associations between sexual assault characteristics and the mental health of survivors have produced inconsistent findings. ${ }^{13}$ Most extant research has examined the impact of a single or a few sexual assault characteristics, ${ }^{6}$ but each incident involved multiple characteristics that were not independent of each other. ${ }^{13}$ A useful analysis of sexual assault characteristics needs to consider the individual's overall experience instead of treating each characteristic independently. The few studies that have applied this approach to date have identified specific subgroups based on 
combinations of sexual assault characteristics. ${ }^{6,12-16}$

The impact of sexual assault victimization on adult survivors' mental health can be distinctively different from that of victimization in childhood. Some studies that have compared adulthood and childhood sexual assault victims' experiences found that the perpetrators of attacks on adults are more likely to be a stranger rather than a relative and are more likely to use a weapon or physical coercion when compared with childhood or adolescent sexual assault perpetrators. ${ }^{17,18}$ In addition, the percentage of reports of rape among adulthood sexual assault victims was higher than that among survivors of childhood and adolescent sexual assaults. ${ }^{16}$ Empirical studies of sexual assault accumulated evidence that the patterns and severity of the negative mental health outcomes caused by sexual assault varies depending on the characteristics of such violence. ${ }^{6,9,19}$ Sexual assault experiences of adults and children tend to have different characteristics and can cause different impacts on the mental health of the survivors. However, mental health outcomes of adult sexual assault survivors have been infrequently addressed by previous research ${ }^{13}$ and this study aims to address such lack of knowledge.

Adult sexual assault is also often associated with high vulnerability to secondary victimization or unfair treatment. Sexual assault survivors may face an arduous experience when they disclose their experience or try to seek help. Secondary victimization is an additional trauma that results from the blame or skeptical attitudes directed toward victims by the legal system, medical professionals, and other community service providers. ${ }^{20} \mathrm{~A}$ growing body of research, enabled by the development of the Social Reactions Questionnaire (SRQ), ${ }^{21}$ has revealed negative social reactions after survivor disclosure of assaults to informal social network members and formal support providers. Negative social reactions reportedly vary according to perpetrator type, ${ }^{22,23}$ secondary victimization experiences can undermine the mental health of survivors, ${ }^{24}$ and negative social reactions are associated with PTSD. ${ }^{25}$

In addition, reports of adverse experiences in childhood, including abuse or neglect, are relatively high in number among adult sexual assault survivors. Numerous studies have reported a connection between childhood sexual abuse (CSA) and adult sexual assault, ${ }^{26}$ although the mechanisms of the connection are not well-understood at this time. ${ }^{14}$ One study of the relationship between adverse childhood experiences (ACEs), which includes CSA, and adult sexual victimization found that each dimension of ACE was associated with adult sexual assault victimization, with CSA being the strongest factor. $^{27}$

These discussions remind us of the importance of focusing on the social as well as the therapeutic perspective in the process of intervening in victims of sexual assault. In addition, if we can identify the differences between different subtypes among victims of sexual assault in this perspective, it can provide implications for intervention or treatment for victims of sexual assault.

This study identified subgroups of survivors using a cluster analysis based on sexual assault characteristics. It was designed to assess subgroup mental health within three months after the assault occurred; the occurrence of secondary victimization following disclosure; and ACEs, including child abuse, sexual abuse, and neglect.

\section{METHODS}

\section{Participants}

The subjects in this study consisted of 1) 122 females who had visited crisis intervention centers for sexual violence in South Korea and 2) 143 females with no history crisis intervention center visitation who served as a comparison group. Female participants older than 18 years of age who reported experiencing a sexual assault within the previous three months were assigned to the sexually assaulted group. Those who had a congenital brain disorder, cerebral palsy, spastic disorder, dysesthesia, autism, history of alcohol or drug abuse, or were pregnant were excluded. Except for sexual assault experiences, the same inclusion and exclusion criteria were applied to the comparison group. The two groups exhibited similar key characteristics at baseline, including age, education, marital status, and socioeconomic status. Researchers gathered informed consent from the participants and explained the purpose of the study according to the guidelines of the Internal Review Board at one of the authors' institutions. Emergency contact information and locations of local mental health centers were provided to the participants. This study was approved by the Institutional Review Board for human subjects at the Sungkyunkwan University (SKKU 2016-06-006-008).

\section{Measures}

\section{Sexual assault experiences}

The characteristics of sexual assault experiences were extracted from the standardized case records management system used in crisis intervention centers. To abstract the detailed characteristics of sexual assault (e.g., action type, relation to the perpetrator, frequency, duration, whether violence and/or alcohol accompanied the assault) from the administrative data, we developed a Korean version of the Sexual Assault Case Records Abstraction Instrument. ${ }^{16,28}$ This instrument is a modified version of the Maltreatment Case Record Abstraction Instrument, ${ }^{29}$ which was based on the Maltreatment Classification System. ${ }^{30}$ The goal was a system that 
could categorize and quantify a large amount of specific data about sexual assault experiences. Employees of victim support centers and trained researchers abstracted the participants' assault experiences. Two of the authors supervised and trained the abstractors and verified their performance. Training consisted of a two-hour extensive orientation and close supervision of the first four or five case abstractions until the abstractors achieved an interrater agreement with the authors of at least $90 \%$ (mean of kappa $=0.982$ ).

\section{Secondary victimization experiences}

Secondary victimization experiences were measured using the Secondary Victimization Questionnaire (SVQ) ${ }^{20}$ and Social Reactions Questionnaire. ${ }^{21}$ To investigate secondary victimization experiences from formal sources, the SVQ assessed four areas. The first and second areas included eight provocative statements (e.g., "encouraged you not to report," "questioned the way you were dressed") aimed at examining secondary victimization behaviors while interacting with the legal system during reporting, the investigation, and trials as well as the level of psychological distress caused by each behavior. Victims who had experienced secondary victimization behaviors reported "yes" and rated the degree of distress on a five-point scale ( $0=$ "not distressed at all" to $4=$ "a great deal of distress"). Victims who answered "yes" and rated their level of distress as greater than two were considered to have experienced secondary victimization. Likewise, the third and fourth areas in the scale included five questions (e.g., "rushed care/not attentive to your emotional state," "did not explain the risk of pregnancy from assault") that measured victims' levels of distress according to the experience of secondary victimization caused by professionals administering medical services. The same criterion was applied to determine the secondary victimization experience status in this context. In addition, six items representing several emotions (e.g., feeling guilty/ blaming oneself, feeling depressed) were used to describe experiences of psychological distress as a result of interactions with the legal and medical systems; these questions were measured using a five-point Likert scale ( $0=$ "not at all" to $4=$ "a great deal"). These cases were then divided into 1 ) secondary victimization behaviors $(\alpha=0.75)$ and the attitude $(\alpha=0.88)$ of the legal system and 2) secondary victimization behaviors $(\alpha=0.75)$ and the attitude $(\alpha=0.95)$ of the medical system.

To assess secondary victimization experiences from the informal social network, this study utilized the SRQ, which poses 26 questions to assess negative social reactions of family members or acquaintances. A five-point Likert scale $(0=$ "never" to $4=$ "always") was used for responses. This study used the Korean version of the SRQ, ${ }^{31}$ which identified five factors, similar to the original version: behavior change (six items; $\alpha=0.84$ ), distracting (seven items; $\alpha=0.88$ ), controlling (seven items; $\alpha=0.64$ ), blaming (four items; $\alpha=0.92$ ), and egocentric responses (four items; $\alpha=0.86$ ).

\section{Adverse childhood experience}

Adverse experiences during childhood were measured by the Adverse Childhood Experiences (ACE) scale. ${ }^{32}$ Numerous studies have used this scale to measure the long-term effects of early trauma. This scale is a composite index of 18 self-reported answers measuring 10 dimensions including childhood physical abuse, parental separation, and another household member suffering a mental illness. Some dimensions have more than one question (e.g., "did a parent or other adult in the household often swear at you, insult you, put you down, or humiliate you?"). The 18 questions were answered using a four-point response scale ( $0=$ "never" to $3=$ "very frequently"). The ACE scale is widely used and has shown good reliability and validity in public health contexts. ${ }^{33-35}$ This study considered the total score $(\alpha=0.96)$ as well as the two subscales of child abuse $(\alpha=0.87)$ and household dysfunction $(\alpha=0.82){ }^{36}$

\section{PTSD}

PTSD was assessed by the Psychometric Properties of the Post-traumatic Diagnostic Scale for the Diagnostic and Statistical Manual of Mental Disorders, Fifth Edition (PDS-5). ${ }^{37}$ Based on the diagnostic standard, 20 questions explored the four specific symptoms of "intense fear," "re-experiencing," "avoidance," and "increased arousal." Participants responded to each item using a five-point Likert scale [0="never happened" to $4=$ "serious (i.e., more than six times in one week)"]. The Cronbach's alpha coefficient for this study was 0.92 .

\section{Depression}

The Center for Epidemiologic Studies Depression (CESD) scale, as developed by Radloff, ${ }^{38}$ is one of the most popular measures of depressive symptoms, capturing levels of depression. This study used a Korean version known as the KCES-D. ${ }^{39}$ The frequency of 20 depressive symptoms was rated on a four-point Likert scale (0-3). Examples of statements included "I was bothered by things that usually don't bother me" and "I felt lonely, like I am alone in the world." Prior researchers have found adequate degrees of internal consistency and reliability for the CES-D scale. ${ }^{38-40}$ The internal consistency for this study was 0.89 .

\section{Anxiety}

This study measured levels of anxiety using the Beck Anxiety Inventory (BAI), which was developed by Beck et al. ${ }^{41}$ The BAI has been found to have acceptable levels of internal 
consistency, reliability, and concurrent validity. ${ }^{41,42}$ The present study used the Korean version of the $\mathrm{BAI},{ }^{43}$ which consists of 21 questions answered using a four-point Likert-type scale (range $0-3 ; \alpha=0.96$ ).

\section{Dissociation}

To measure the frequency of dissociation experiences, this study employed the Korean version of the Dissociative Experience Scale-II (DES-II). The original scale was developed by Carlson and Putnam. ${ }^{44}$ DES-II is designed to provide a convenient way to quantify dissociation experiences by measuring the percentage of time participants have dissociation experiences. Statements to respond to include "some people have the experience of finding themselves in a place and having no idea how they got there" and "some people have the experience of feeling that their body does not seem to belong to them." The Cronbach's alpha coefficient for the Korean version of the scale (K-DES-II) used by Kim et al. ${ }^{45}$ was 0.94 , while the value of the coefficient in this study was 0.95 .

\section{Alcohol misuse}

To measure levels of alcohol abuse, the present study employed the CAGE questionnaire. ${ }^{46}$ CAGE (an acronym for its four questions) is a concise and reliable assessment instrument for identifying alcohol problems. Questions include "have you ever felt you needed to cut down on your drinking?" and "have people annoyed you by criticizing your drinking?" The four items are rated on a binary scale $(0=$ no and $1=$ yes) with a higher percentage of "yes" responses indicating the existence of a problem with alcohol. The test-retest reliability for CAGE conducted by Dhalla and Copec $^{47}$ ranged between 0.80 and 0.95. CAGE was also highly correlated with the other screening scales $(\mathrm{r}=0.70)$. The Cronbach's alpha coefficient for this study was 0.76 .

\section{Psychoticism}

The present study utilized the Personality Psychopathology 5 (PSY-5) scale developed by Harkness et al. ${ }^{48}$ to provide a dimensional description for personality and its disorders. This scale includes five dimensions: aggressiveness, psychoticism, disconstraint, negative emotionality and neuroticism, and introversion and low positive emotionality. PSY-5 psychoticism ( $0=$ no and $1=y e s)$, consisting of six items, assesses the disconnection from reality with respect to unusual sensory and perceptual experiences, unshared beliefs with others, alienation, and unrealistic expectations of harm. Examples of questions include "has anyone ever said that what you are believing is not real?" and "have you ever thought that you have special powers, unlike others?" Higher rates of "yes" responses indicate more severe psychoticism. The value of the internal consistency coefficient in this study was 0.60 .

\section{Eating disorders}

The current study employed the Eating Disorder Screen for Primary Care (ESP) tool to measure the level of disordered eating. ${ }^{49}$ The ESP asks five questions (e.g., "do you ever eat in secret?", "how satisfied are you with your eating habits?") to be answered using a binary scale ( $0=$ no and $1=y e s)$. A higher rate of "yes" responses indicated a higher level of disordered eating. In this study, the Cronbach's alpha coefficient was 0.56 .

\section{Suicide risk}

To measure the degree of suicide risk, this study adopted the Columbia Suicide Severity Rating Scale (C-SSRS). ${ }^{50}$ The C-SSRS was originally developed to capture certain factors related to suicidal behaviors and thoughts ${ }^{51}$ by measuring three constructs (suicidal ideation, suicidal behavior, and nonsuicidal self-injury) with 19 questions ( $0=$ no and $1=y e s)$. Questions include "have you wished you were dead or that you could go to sleep and not wake up?" "have you made a suicide attempt?", and "did you do it purely for other reasons/without any intention of killing yourself (e.g., relieve stress, feel better, get sympathy)?" For suicidal ideation, the participants who answered "yes" to one of the five questions indicating the severity of suicidal thoughts were regarded as expressing suicidal ideations. The current study summated the other four questions, set a score of greater than one point as suggesting serious suicidal behavior, and used the remaining questions to measure self-harm. This study used a Korean version of the C-SSRS devised by Pai et al. ${ }^{52}$ and divided suicide risk into suicidal ideation, suicidal behavior, and non-suicidal self-injurious behavior. The C-SSRS showed adequate internal consistency for adolescents and adults. ${ }^{50}$ In this study, the Cronbach's alpha coefficients for suicidal ideation and suicidal behavior were 0.86 and 0.83 , respectively.

\section{Analysis plan}

The analysis in this investigation involved two steps. First, profile analysis was performed on 112 sexual assault victims out of the 225 total research participants. This included type of use, primary provider, frequency, and age of onset, etc. The rest of the participants were comparison group and were not included in the profile analysis because they had no experience of sexual assault. Using such an approach could identify specific subgroups by sexual assault characteristics. Second, categorical and continuous variables were mixed. Twostep cluster analysis used log-likelihood distance and a function that incorporated two levels of variables in the same model. To identify outliers during cluster analysis, a cluster feature 
tree was employed. A Bayesian inference criterion, an index that provides assistance when choosing between competing models, was estimated.

The present study measured mean values of psychosocial characteristics to determine the difference between members of four sexually assaulted subgroups and the comparison group. It investigated the differences in mean values of the sexually assaulted subgroups according to secondary victimization and adverse childhood experiences. Profile subgroup differences in mental health variables were also observed. For this investigation, PROC GLM and chi-squared tests were used ${ }^{53}$ to encompass both categorical and continuous dependent variables. We aimed to identify group differences in psychosocial characteristics while holding the perceived socioeconomic status constant. Post-hoc analysis exploring differences between multiple group means was used if the main effects were statistically significant for psychosocial characteristics. ${ }^{54}$ For multiple-comparison testing, the Bonferroni alpha correction was employed.

\section{RESULTS}

\section{Demographic characteristics}

Demographic characteristics of the participants are presented in Table 1. Except for socioeconomic status, the sexually assaulted group and the comparison group did not show significant differences. The average age of the study population was 25.2 (standard deviation: 7.0 ) years. About $57 \%$ of

Table 1. Demographic characteristics of the study participants

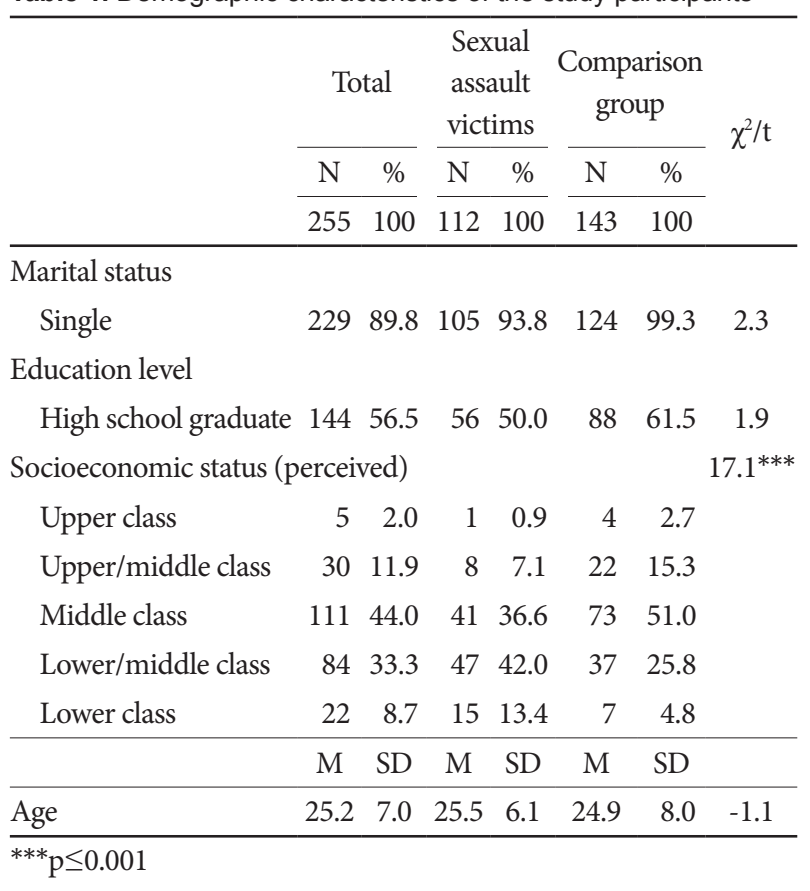

the participants were high-school graduates and almost 90\% were single (Table 1). In terms of socioeconomic status, most of the participants were in the middle class, while more women in the sexual assault group reported their status as lowermiddle or lower class than did the comparison women ( $42.0 \%$ vs. $25.7 \%$ for lower-middle class; $13.4 \%$ vs. $4.8 \%$ for lower class) (Table 1$)$. These results were statistically significant $\left(\chi^{2}=\right.$ $17.1 ; \mathrm{p}<0.001)$.

\section{Characteristics of profile groups}

Table 2 presents profile groups of 112 cases based on sexual assault characteristics. The results identified four different profile subgroups. Profile 1 (P1) consisted of victims who experienced sexual touching by colleagues, friends, or acquaintances. The average age of onset in Profile 1 was higher than that of other groups. As with Profile 1, Profile 2 (P2) showed a high frequency of one-time sexual assault and all victims had experienced rape by a colleague, friend, or peer. The average age of rape in Profile 2 was the lowest among all groups. Profile 3 (P3) involved victims who had experienced rape in the context of an intimate relationship. Finally, similar to Profile 2, victims in Profile 4 (P4) experienced rape, but most perpetrators were strangers. Given this result, the present study designated the four subgroups as sexual touching (P1), rape/social relation (P2), intimate partner violence (IPV) (P3), and rape/stranger (P4), respectively.

To investigate the characteristics of each profile group in detail, we examined additional factors of physical violence accompanying the sexual assault incident and alcohol or drug use. The results indicate that alcohol and drugs were common in each profile group. The rape/stranger group (94.3\%) displayed the highest frequency of alcohol and drug use, followed by rape/social relation (88.2\%). However, the rate of physical violence (17.95\%) during sexual assault was lower than the rate of alcohol and drug use. The IPV group showed the highest frequency of physical violence (47.6\%), followed by the sexual touching (13.6\%), rape/stranger (11.4\%), and rape/social relation (8.8\%) groups, respectively.

\section{Group comparisons of secondary victimization and adverse childhood experiences}

Table 3 and Figure 1 present group differences in the areas of secondary victimization and adverse childhood experiences. First, this study found that profile groups showed no significant differences in SVQ legal emotion and SVQ medical behavior and emotion; instead, only differences in SVQ legal behavior were statistically significant. To see the results in detail, several characteristics can be identified. For example, P3 (IPV) had the highest mean score in the areas of secondary victimization. In terms of SVQ legal behavior, P3 (IPV) 
Table 2. Profile analysis of sexual assault victims $(\mathrm{N}=112)$

\begin{tabular}{|c|c|c|c|c|c|c|c|c|c|c|}
\hline & \multicolumn{2}{|c|}{ Total } & \multicolumn{2}{|c|}{$\begin{array}{c}\text { Profile } 1 \\
\text { sexual touching }\end{array}$} & \multicolumn{2}{|c|}{$\begin{array}{c}\text { Profile } 2 \\
\text { rape/social relation }\end{array}$} & \multicolumn{2}{|c|}{$\begin{array}{c}\text { Profile } 3 \\
\text { IPV }\end{array}$} & \multicolumn{2}{|c|}{$\begin{array}{c}\text { Profile } 4 \\
\text { rape/stranger }\end{array}$} \\
\hline & $\mathrm{N}$ & $\%$ & $\mathrm{~N}$ & $\%$ & $\mathrm{~N}$ & $\%$ & $\mathrm{~N}$ & $\%$ & $\mathrm{~N}$ & $\%$ \\
\hline & 112 & 100 & 22 & 19.6 & 34 & 30.4 & 21 & 18.8 & 35 & 31.3 \\
\hline \multicolumn{11}{|l|}{ Types of abuse } \\
\hline Sexual touching & 20 & 17.9 & 19 & 86.4 & 0 & 0 & 1 & 4.8 & 0 & 0 \\
\hline Rape & 92 & 82.1 & 3 & 13.6 & 34 & 100 & 20 & 95.2 & 35 & 100 \\
\hline \multicolumn{11}{|l|}{ Primary perpetrator } \\
\hline Intimate partner & 20 & 18.0 & 0 & 0 & 0 & 0 & 20 & 95.2 & 0 & 0 \\
\hline Colleague, friend, peer & 55 & 49.6 & 18 & 81.8 & 34 & 100 & 1 & 4.8 & 2 & 5.9 \\
\hline Stranger & 36 & 18.9 & 4 & 18.2 & 0 & 0 & 0 & 0 & 32 & 94.1 \\
\hline \multicolumn{11}{|l|}{ Frequency } \\
\hline One time only & 100 & 89.3 & 20 & 90.9 & 32 & 94.1 & 13 & 61.9 & 35 & 100 \\
\hline More than two times & 9 & 8.0 & 2 & 9.1 & 2 & 5.9 & 5 & 23.8 & 0 & 0 \\
\hline Several times a month & 1 & 0.9 & 0 & 0 & 0 & 0 & 1 & 4.8 & 0 & 0 \\
\hline \multirow[t]{2}{*}{ Several times a week } & 2 & 1.8 & 0 & 0 & 0 & 0 & 2 & 9.5 & 0 & 0 \\
\hline & M & SD & M & SD & M & SD & M & SD & $\mathrm{M}$ & SD \\
\hline \multirow[t]{2}{*}{ Age at onset } & 24.2 & 6.3 & 26.7 & 10.4 & 22.2 & 3.0 & 24.0 & 6.8 & 24.6 & 4.4 \\
\hline & $\mathrm{N}$ & $\%$ & $\mathrm{~N}$ & $\%$ & $\mathrm{~N}$ & $\%$ & $\mathrm{~N}$ & $\%$ & $\mathrm{~N}$ & $\%$ \\
\hline \multicolumn{11}{|l|}{ Physical violence } \\
\hline Any violence & 20 & 17.9 & 3 & 13.6 & 3 & 8.8 & 10 & 47.6 & 4 & 11.4 \\
\hline \multicolumn{11}{|l|}{ Alcohol and/or drug } \\
\hline Any alcohol/or drug & 86 & 76.8 & 12 & 54.5 & 30 & 88.2 & 11 & 52.4 & 33 & 94.3 \\
\hline
\end{tabular}

Table 3. Group adjusted raw score mean and standard deviation for adverse childhood experience and secondary victimization variables

\begin{tabular}{|c|c|c|c|c|c|c|c|c|c|c|c|}
\hline & \multicolumn{2}{|c|}{$\begin{array}{c}\text { Profile } 1 \\
\text { sexual touching } \\
\end{array}$} & \multicolumn{2}{|c|}{$\begin{array}{c}\text { Profile } 2 \\
\text { rape/social relation }\end{array}$} & \multicolumn{2}{|c|}{$\begin{array}{c}\text { Profile } 3 \\
\text { IPV }\end{array}$} & \multicolumn{2}{|c|}{$\begin{array}{c}\text { Profile } 4 \\
\text { rape/stranger }\end{array}$} & \multicolumn{2}{|c|}{ Comparison } & \multirow[t]{2}{*}{$\mathrm{R}^{2}$} \\
\hline & M & SD & M & SD & $\mathrm{M}$ & SD & M & $\mathrm{SD}$ & $\mathrm{M}$ & $\mathrm{SD}$ & \\
\hline SVQ_legal_behavior & 1.6 & 2.4 & 2.3 & 2.3 & $2.5^{\|}$ & 2.4 & $1.1^{\S}$ & 1.0 & - & - & $0.07^{*}$ \\
\hline SVQ_legal_emotion & 13.4 & 7.0 & 13.5 & 6.2 & 14.4 & 5.6 & 12.5 & 6.0 & - & - & 0.01 \\
\hline SVQ_medical_behavior & 0.2 & 0.8 & 0.8 & 1.4 & 0.9 & 1.2 & 0.3 & 0.6 & - & - & 0.07 \\
\hline SVQ_medical_emotion & 6.6 & 8.3 & 10.1 & 7.5 & 10.2 & 7.2 & 8.2 & 6.8 & - & - & 0.04 \\
\hline SRQ_victim blame & 3.8 & 4.9 & 4.7 & 6.2 & $6.9^{\| \prime}$ & 5.1 & $3.1^{\S}$ & 4.4 & - & - & $0.07^{*}$ \\
\hline SRQ_distraction & 6.9 & 5.4 & 6.8 & 7.9 & 7.6 & 6.3 & 5.1 & 4.5 & - & - & 0.01 \\
\hline SRQ_behavior change & $1.1^{\ddagger}$ & 1.6 & $3.3^{\dagger}$ & 4.3 & 3.0 & 4.0 & 1.5 & 2.0 & - & - & $0.08^{*}$ \\
\hline SRQ_egocentric reaction & 7.3 & 5.2 & 6.8 & 4.2 & 4.7 & 3.1 & 5.4 & 4.0 & - & - & 0.04 \\
\hline SRQ_take control & 3.5 & 3.6 & 4.5 & 5.1 & 4.0 & 2.5 & 3.0 & 2.4 & - & - & 0.04 \\
\hline SRQ_total & 23.2 & 14.1 & 27.0 & 22.0 & 26.7 & 16.9 & 18.7 & 12.6 & - & - & 0.05 \\
\hline ACE_Child abuse & 1.8 & 1.2 & $2.5^{\pi}$ & 1.5 & $3.0^{11 \pi}$ & 1.4 & $1.5^{\S}$ & 1.3 & $1.2^{\ddagger \S}$ & 1.3 & $0.15^{* * *}$ \\
\hline _Sexual abuse & 0.5 & 1.3 & $0.6 \pi$ & 1.2 & $0.8 \pi$ & 1.2 & 0.4 & 0.7 & $0.1 \neq \S$ & 0.3 & $0.09^{* * *}$ \\
\hline ACE_Dysfunction & 2.0 & 2.3 & $1.8^{\S}$ & 3.1 & $3.8^{ \pm 1 \| \pi}$ & 3.6 & $1.8^{\S}$ & 2.9 & $1.3^{\S}$ & 2.5 & $0.14^{* * *}$ \\
\hline ACE_Total & $3.5^{\S}$ & 0.7 & $4.1^{\pi}$ & 0.5 & $6.6^{+11 \pi}$ & 0.7 & $3.3^{\S}$ & 0.5 & $2.0^{\ddagger \S}$ & 0.2 & $0.18^{* * *}$ \\
\hline
\end{tabular}
${ }^{*} \mathrm{p} \leq 0.05,{ }^{* * *} \mathrm{p} \leq 0.001,{ }^{\dagger}$ Different from P1, $\mathrm{p}<0.05$, ${ }^{\ddagger}$ Different from P2, $\mathrm{p}<0.05$, § Different from P3, $\mathrm{p}<0.05$, "Different from 4, $\mathrm{p}<0.05,{ }^{\mathrm{T}} \mathrm{Different}$ from comparison, $\mathrm{p}<0.05$. SVQ: Secondary Victimization Questionnaire, SRQ: Social Reactions Questionnaire, ACE: adverse childhood experience 


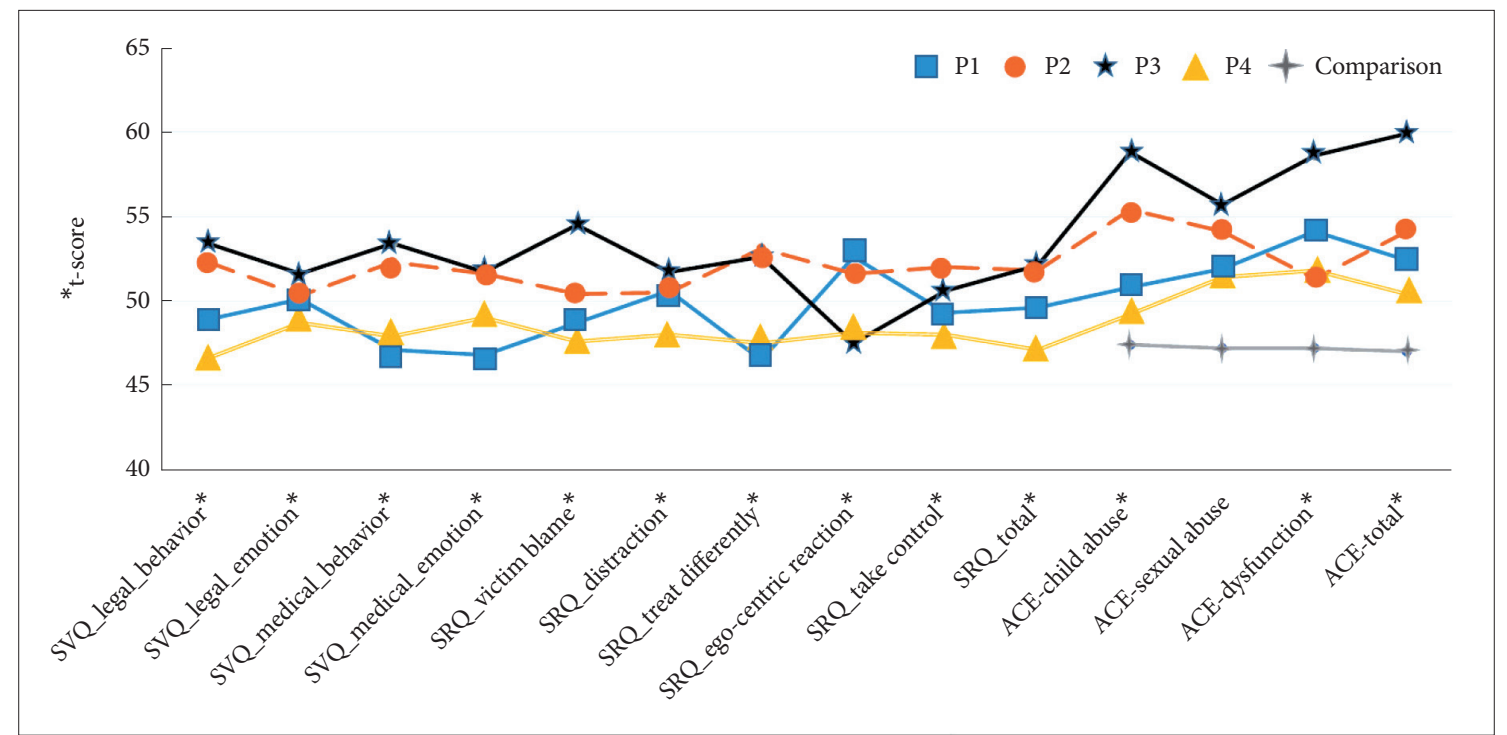

Figure 1. Adverse childhood experience and secondary victimization scores of groups. SVQ: Secondary Victimization Questionnaire, SRQ: Social Reactions Questionnaire, ACE: adverse childhood experience.

showed a higher mean score (2.5) for secondary victimization as compared with P4 (rape/stranger) (1.1, F=3.13; p=0.049). P2 (rape/social relation) exhibited the second highest mean score for 1) SVQ legal behavior (2.3) and emotion (13.5) and 2) SVQ medical behavior (0.8) and emotion (10.2). P4 (rape/ stranger), where the assault situation involved an unknown perpetrator, showed lower mean scores than those of P1 (sexual touching) in SVQ legal behavior and emotion. Second, while not statistically significant, P1 had the lowest mean scores for SVQ medical behavior (0.2) and emotion (6.6) - that is, although no significant differences were found between P1 and P4 for SVQ medical behavior and emotion, it is reasonable to assume that the other profile groups experiencing rape required more medical assistance than did those individuals included in P1.

Next, differences among profile subgroups were evident in the SRQ responses with respect to victim-blaming and behavior changes. The results showed patterns that were analogous to SVQ legal and medical factors. For example, P3 had the highest mean score (6.9) for SRQ victim-blaming (F= 3.90; $\mathrm{p}=0.049$ ), which was significantly different from that of $\mathrm{P} 4$ (3.1). In regard to behavior change, the difference between the mean scores of P2 (3.3) and P1 (1.1) was statistically significant. Moreover, P1 (1.1) had a lower mean score than P4 (1.5), and this was different from the previous result. However, except for SRQ behavior change scores, P1 showed greater mean scores than P4 for all of the SVQ measures.

This pattern was especially prominent in the areas of ACE. The result showed at least one difference in the mean score between the profile groups and the comparison group for ACE child abuse (1.2, $\mathrm{F}=8.6 ; \mathrm{p}=0.001)$, sexual abuse $(0.1, \mathrm{~F}=7.4$; $\mathrm{p}=0.001)$, household dysfunction $(1.3, \mathrm{~F}=7.4 ; \mathrm{p}=0.001)$, and total $(2.0, \mathrm{~F}=9.6 ; \mathrm{p}=0.001)$. In particular, the comparison group had lower mean scores compared with the profile groups in the areas of ACE, with the size of the group difference ranging from two- to 10-fold. P3 showed the highest mean score in all areas of ACE. This was particularly the case in ACE child abuse (3.0, $\mathrm{F}=8.6 ; \mathrm{p}=0.001)$ and ACE total (6.6, $\mathrm{F}=9.6 ; \mathrm{p}=$ 0.001).

Not only was P3 significantly different from the comparison group with respect to ACE sexual abuse $(\mathrm{F}=5.8 ; \mathrm{p}=0.001)$, but P3 (mean=3.8) was also significantly different from P4 (1.8) and P2 (1.8) in terms of ACE dysfunction ( $\mathrm{F}=7.4 ; \mathrm{p}=0.001)$. No group difference was found regarding ACE dysfunction between $\mathrm{P} 1, \mathrm{P} 4$, and the comparison group.

\section{Group comparison regarding mental health}

Table 4 and Figure 2 display group differences in mental health scores between the profile and comparison groups. The results, which were similar to the previous findings for ACE, can be explained based on sexual assault characteristics. For example, except for the disordered eating variable (ESP), at least one profile group exhibited higher mean scores than the comparison group for all mental health variables. In fact, the comparison group exhibited lower mean scores than the profile groups for PTSD (5.9, $\mathrm{F}=106.4 ; \mathrm{p}=0.001)$, depression $(\mathrm{CES}-\mathrm{D})(14.9, \mathrm{~F}=33.2 ; \mathrm{p}=0.001)$, anxiety $(\mathrm{BAI})(6.8, \mathrm{~F}=$ $30.5 ; \mathrm{p}=0.001)$, and dissociation (DES-II) (27.6, $\mathrm{F}=12.3 ; \mathrm{p}=$ 0.001 ). The average difference between the profile groups and the comparison group for the PTSD variable was up to seven, which increased the value of the coefficient of determination $\left(\mathrm{R}^{2}=0.65\right)$. 
K Kim et al.

Table 4. Groups adjusted raw score mean and standard deviation for mental health variables

\begin{tabular}{|c|c|c|c|c|c|c|c|c|c|c|c|}
\hline & \multicolumn{2}{|c|}{$\begin{array}{c}\text { Profile } 1 \\
\text { sexual touching }\end{array}$} & \multicolumn{2}{|c|}{$\begin{array}{c}\text { Profile } 2 \\
\text { rape/social relation }\end{array}$} & \multicolumn{2}{|c|}{$\begin{array}{l}\text { Profile } 3 \\
\text { IPV }\end{array}$} & \multicolumn{2}{|c|}{$\begin{array}{c}\text { Profile } 4 \\
\text { rape/stranger }\end{array}$} & \multicolumn{2}{|c|}{ Comparison } & \multirow[t]{2}{*}{$\mathrm{R}^{2}$} \\
\hline & $\mathrm{M}$ & $\mathrm{SD}$ & $\mathrm{M}$ & SD & $\mathrm{M}$ & $\mathrm{SD}$ & M & $\mathrm{SD}$ & $\mathrm{M}$ & SD & \\
\hline$\overline{\mathrm{PTSD}}$ & $42.7 \pi$ & 19.4 & $43.4^{\pi}$ & 16.8 & $41.8^{\pi}$ & 14.5 & $39.5^{\pi}$ & 15.4 & $5.9^{\dagger \neq \S \|}$ & 9.1 & $0.65^{* * *}$ \\
\hline CES-D & $32.4^{\pi}$ & 15.1 & $35.8^{\pi}$ & 13.2 & $34.8^{\pi}$ & 10.9 & $31.5^{\pi}$ & 12.6 & $14.9^{\dagger \neq \S \Perp}$ & 10.3 & $0.41^{* * *}$ \\
\hline BAI & $22.1^{\pi}$ & 15.3 & $23.5^{\pi}$ & 14.6 & $27.2^{\| \pi}$ & 12.3 & $19.6^{\S \pi}$ & 12.2 & $6.8^{\dagger \ddagger \S \|}$ & 7.6 & $0.36^{* * *}$ \\
\hline DES-II & $46.38 \pi$ & 37.4 & $60.4^{\pi}$ & 50.2 & $72.7^{+11 \pi}$ & 50.0 & 53.0 §ा & 40.0 & $27.6^{\ddagger £ \S \|}$ & 24.3 & $0.18^{* * *}$ \\
\hline CAGE & $1.0 \neq \S \|$ & 0.2 & $2.0^{+\pi}$ & 0.1 & $2.2+\pi$ & 0.2 & $2.4^{+\pi}$ & 0.1 & $0.8^{\dagger \S} \|$ & 0.1 & $0.25^{* * *}$ \\
\hline ESP & 2.2 & 1.2 & 2.1 & 1.2 & 2.3 & 1.1 & 2.2 & 1.2 & 1.7 & 1.1 & 0.04 \\
\hline PSY & $1.0^{\pi}$ & 1.0 & $1.0^{\pi}$ & 1.1 & $1.1^{\pi}$ & 1.5 & 0.6 & 1.0 & $0.3^{\dagger \neq \S}$ & 0.6 & $0.11^{* *}$ \\
\hline \multirow[t]{2}{*}{ CSSRS_ideation } & 2.3 & 2.1 & $2.8 \pi$ & 1.8 & $3.0 \pi$ & 1.6 & 1.7 & 1.8 & $1.3^{\ddagger \S}$ & 1.6 & $0.17^{* *}$ \\
\hline & $\mathrm{N}$ & $\%$ & $\mathrm{~N}$ & $\%$ & $\mathrm{~N}$ & $\%$ & $\mathrm{~N}$ & $\%$ & $\mathrm{~N}$ & $\%$ & \\
\hline CSSRS_behavior & 7 & 33.3 & 13 & 38.2 & 12 & 57.1 & 6 & 17.1 & 17 & 11.9 & $31.2^{* * *}$ \\
\hline CSSRS_self-injury & 5 & 23.8 & 10 & 29.4 & 5 & 23.8 & 4 & 11.4 & 11 & 7.7 & $15.1^{* *}$ \\
\hline
\end{tabular}

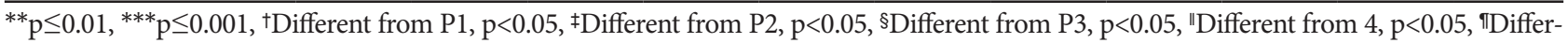
ent from comparison, $\mathrm{p}<0.05$. PTSD: Post-traumatic stress disorder, CES-D: Center for Epidemiologic Studies Depression, BAI: Beck Anxiety Inventory, DES-II: Dissociative Experience Scale-II, CAGE: Cut-Annoyed-Guilty-Eye, ESP: Eating disorder Screen for Primary care, PSY: Personality Psychopathology, CSSR: Columbia-Suicide Severity Rating Scale

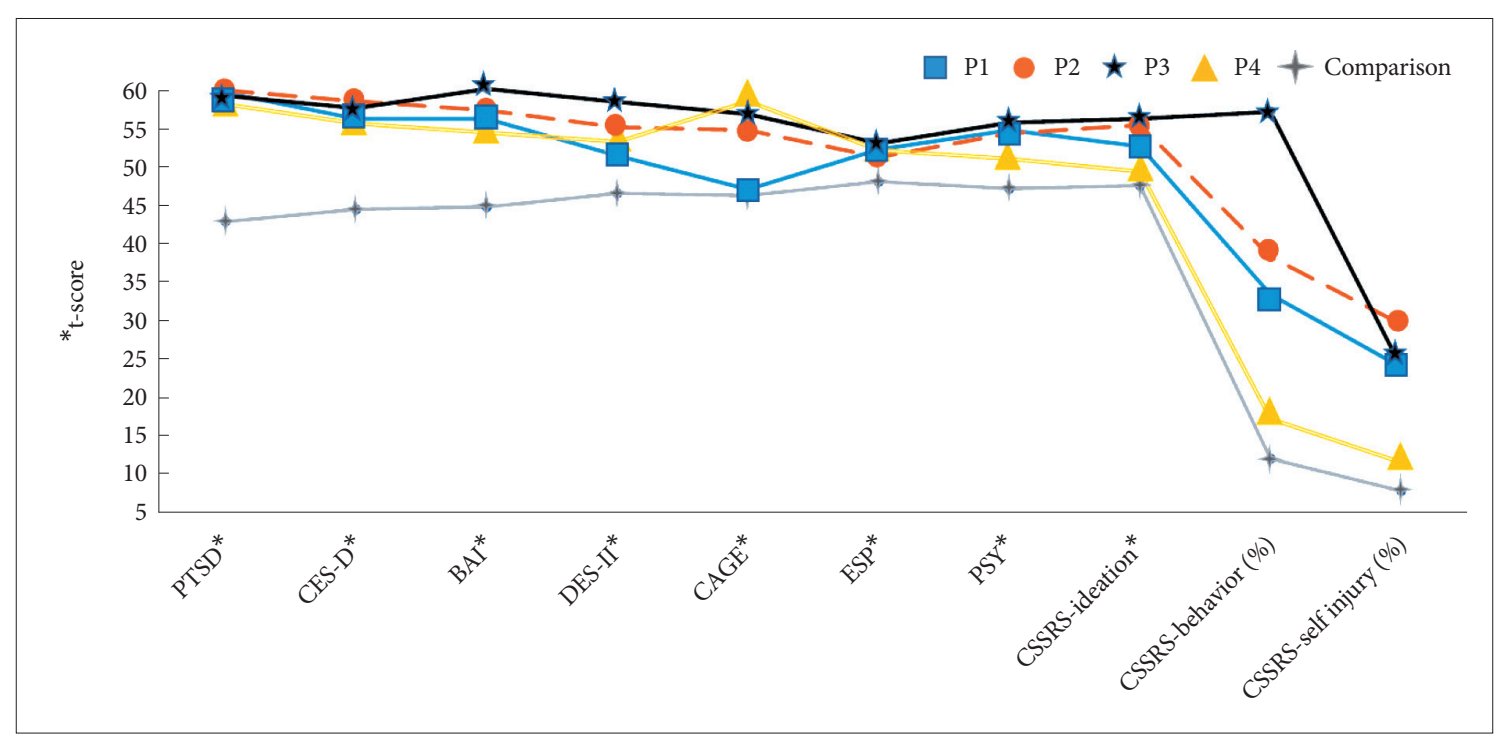

Figure 2. Mental health scores of assault profile groups and comparison group. PTSD: Post-Traumatic Stress Disorder, CES-D: the Center for Epidemiologic Studies-Depression scale, BAl: Beck Anxiety Inventory, DES-II: Dissociative Experiences Scale II, CAGE: Cut-AnnoyedGuilty-Eye, ESP: Eating disorder Screen for Primary care, PSY: Personality Psychopathology, CSSR: Columbia-Suicide Severity Rating Scale.

The mean score differences in the profile groups were similar to the previous findings. First, post-hoc and chi-squared tests indicated that P3 had high mean scores. For example, P3 scored highest in anxiety (27.2), dissociation (72.2), suicidal ideation (3.0, $\mathrm{F}=6.3 ; \mathrm{p}=0.001$ ), and suicidal behavior $\left(57.1 \%, \chi^{2}=31.2 ; \mathrm{p}=0.001\right)$. Likewise, although P2 did not show substantially different mean scores from those of other groups, it tended to demonstrate high mean scores in depression (35.8), anxiety (23.5), dissociation (60.4), psychoticism (PSY) (1.0), suicidal ideation (2.8), and suicidal behavior
(38.2\%). P2 displayed the highest rate of self-injury (29.4\%, $\left.\chi^{2}=15.1 ; \mathrm{p}=0.001\right)$. Third, $\mathrm{P} 1$ and $\mathrm{P} 4$ had relatively low mean scores relative to $\mathrm{P} 3$ and $\mathrm{P} 2$. As previously mentioned, members of $\mathrm{P} 4$ experiencing incidents of rape exhibited similar patterns in which the mean scores were comparable to those of P1 experiencing sexual touching and those of the comparison group without a history of sexual assault. P4 scores were lowest among all profile groups in PTSD (39.5), depression (31.5), and anxiety (19.6). Moreover, P4 showed mean scores similar to those of the comparison group in psychoticism (0.6, 
$\mathrm{F}=7.6 ; \mathrm{p}=0.001$ ), suicidal ideation (1.7), suicidal behavior (17.1\%), and self-injury (11.4\%). When comparing simple mean differences of mental health, P1 had relatively higher mean scores than P4 but lower than those of P2 and P3. However, $\mathrm{P} 4$ scored highest of all groups in alcohol abuse (CAGE) ( $m e a n=2.4, F=21.2 ; \mathrm{p}=0.001$ ). This result is remarkable given that $\mathrm{P} 4$ and $\mathrm{P} 1$ displayed similar patterns of mental health.

\section{DISCUSSION}

This study explored subtypes of sexual assault experiences among 255 adult sexual violence victims who utilized intervention services and their comparison group. Four distinctive profile groups-Sexual Touching (19.6\%), Rape/Social Relation (30.4\%), IPV (18.8\%), and Rape/Stranger (31.3\%)were identified. The IPV subgroup experienced physical violence accompanying the sexual assault most frequently. The subgroups differed in terms of secondary victimization and adverse childhood experiences. The Rape/Social Relation and IPV subgroups experienced the most severe secondary victimization. The same tendency was detected with regard to childhood adversity. Especially, the IPV subgroup consistently showed the most elevated level of ACE subscales. In terms of mental health, the four subgroups consistently showed the worst mental health across multiple areas relative to the comparison group. Especially, the IPV subgroup showed the worst outcomes when considering trauma-related symptoms such as anxiety, dissociation, and suicidal attempt.

We identified the four listed profile subgroups based on detailed sexual assault characteristics. This suggests that experiences of sexual assault victims vary under the single category of "sexual assault." The term "sexual assault" is more likely to be concealing than revealing. Women experience a total amalgam of assault experiences in which type, frequency, relationship with perpetrators, and duration are all integral parts. One characteristic of sexual assault cannot properly represent an experience of sexual assault and, especially, the severity of sexual assault, which has long been the way in which extant research operationalizes the concept of sexual assault experiences.

Interestingly, we also observed subgroup differences among secondary victimization experiences. Overall, the Rape/Social Relation and IPV subgroups tended to report the most severe secondary victimization. The IPV subgroup showed a higher rate of secondary victimization experiences than the Rape/Stranger subgroup both in the formal service system and informal network. Some theoreticians and researchers have noted rape myth acceptance as an important mechanism of secondary victimization following disclosure of sexual assault ${ }^{55-57}$ In other words, society currently does not treat all sexual assault cases equally. Public perception of sexual assault involves a violent perpetrator who is a stranger attacking a victim with a weapon and leaving visible physical marks and injuries on the victim. When the case adheres to this stereotypical image, the likelihood that a victim will receive services and support increases. Otherwise, the victims are often doubted and blamed for their violent experiences. The present result may reflect this tendency. As the result shows, actual experiences of sexual assault are diverse. Cases of rape in social relations or intimate relationships consist of a considerable part of the sample. The Rape/Stranger subgroup consistently showed a lower rate of secondary victimization experiences. The current results support the notion of rape myth acceptance as an important mechanism of secondary victimization. Future studies are needed to corroborate this speculation and further elucidate the mechanism of secondary victimization.

A similar tendency is observed in the relationships between profile subgroups and mental health outcomes. The four profile subgroups demonstrated different relationships with mental health outcomes, with a complicated pattern. Overall, all four subgroups of sexual assault victims showed higher levels of PTSD, depression, anxiety, dissociation, and suicide than the comparison group. The Rape/Social Relation and IPV subgroups tended to report more elevated levels in many outcomes than the other two subgroups. The IPV subgroup showed the most heightened levels in some of the mental health outcomes, with higher levels of anxiety than in the Rape/ Stranger subgroup. In terms of dissociation, the IPV reported a higher level in comparison with the Sexual Touching and Rape/Stranger subgroups. However, a considerable proportion of victims in the Sexual Touching subgroup reported suicidal behavior and self-injury. In terms of alcohol misuse, the Sexual Touching group demonstrated the lowest level among the profile subgroups.

This suggests that mental health sequelae may differ depending on the profile subgroup based on sexual assault characteristics, which cannot be simply reduced to the "severity" of a sexual assault experience. People often consider sexual touching to be a mild form of sexual assault relative to rape. However, the levels of mental health outcomes between the Sexual Touching and Rape/Stranger subgroups were comparable in many indices. The rates of suicide attempt and self-injury in Sexual Touching were higher than in the Rape/Stranger group. Although IPV is often not considered sexual assault, the women in that group consistently showed the worst outcomes in many mental health outcomes. This implicates that there may not be a mild form of sexual assault in terms of mental health sequelae. This study is exploratory in nature. Future research needs to elucidate these complicated patterns of relationships between sexual assault experiences and mental 
health outcomes. We also need to determine the relative importance of sexual assault characteristics when compared with secondary victimization as well as adverse childhood experiences. Elklit and Christiansen ${ }^{58}$ theorized that both sexual assault experiences as well as pre- and post-assault experiences should be considered to accurately understand determinants of victims' mental health. This calls for future research examining the relationship in the context of the totality of victims' experiences accompanying sexual violence. These factors involve childhood adversity, detailed characteristics of sexual assault, and the social response following the disclosure of the assault. ${ }^{58}$ Such research will provide valuable information for prioritizing intervention targets and appropriately allocating agency resources to support the recovery of sexual assault victims.

The current study implicates that the dictum of "one size may not fit all" may be well-suited for developing and improving intervention programs for sexual assault victims. It is imperative to develop intervention services customized to different profile groups with different assault experiences and thereby mental health sequelae. It is obvious that such programs should be based on sound scientific evidence that is sensitive to the diversity of sexual assault experiences among women and to capture the totality of the women's experiences.

Despite its potential to contribute to intervention programs to promote victim mental health, important caveats of the present study deserve mention. Because of the exploratory nature of the study, the current results need to be replicated with a larger and longitudinal sample as well as by using a confirmatory analysis approach. The generalizability of the study was significantly limited by recruiting study participants from crisis intervention centers in South Korea. Still, the presented approach could help researchers avoid inaccuracy and incredibility during the retrospective self-reporting of sexual assault experiences. However, it is well-known that a considerable number of sexual assault victims do not seek outside help after their assault. The current findings need to be replicated among sexual assault victims who refuse to disclose their experiences. In addition, it is necessary to recall that the analytical control of the mental health variables covered in this study was insufficient. For example, in the case of PTSD, the previous history of mental disorders can cause more serious damage to individuals already vulnerable. Control of 143 non-comparative groups that have not been put into profile analysis is also necessary. Although the group is subject to no experience in sexual assault, there is a limit to the formation of a comparative group based on a history of mental disorders. In a similar context, comparison of characteristics between groups using a screening scale cannot be seen as a complete representation of the characteristics of each group participant. Therefore, attention is needed to interpret the results. Finally, as this study used a South Korean sample, the study needs to be replicated in many different cultural contexts to provide evidence of cross-cultural similarities in the mechanism of secondary victimization.

\section{Acknowledgments}

This work was supported by the National Research Foundation of Korea (2019-S1A5A2A03-2019S1A5A2A03045289) and partly the Korea Mental Health Technology R\&D (ID: HM15C1107).

\section{Conflicts of Interest}

The authors have no potential conflicts of interest to disclose.

\section{Author Contributions}

Conceptualization: Kihyun Kim. Data curation: Bee Ryou. Formal analysis: Bee Ryou. Funding acquisition: Jae-Won Kim, Kihyun Kim. Investigation: Kihyun Kim, Bee Ryou, Jae-Won Kim. Methodology: Kihyun Kim, Bee Ryou. Project administration: Bee Ryou. Resources: Jae-Won Kim. Software: Bee Ryou. Supervision: Kihyun Kim, Jihyeon Choi, Jae-Won Kim. Validation: Kihyun Kim. Writing_original draft: Kihyun Kim, Bee Ryou. Writing-review \& editing: Jihyeon Choi.

\section{ORCID iDs}

\section{Kihyun Kim}

Bee Ryou

Jihyeon Choi

Jae-Won Kim https://orcid.org/0000-0001-7193-3842 https://orcid.org/0000-0002-2974-018X https://orcid.org/0000-0002-4756-8416 https://orcid.org/0000-0001-8821-6225

\section{REFERENCES}

1. Smith SG, Zhang X, Basile KC, Merrick MT, Wang J, Kresnow MJ, et al. The National Intimate Partner and Sexual Violence Survey: 2015 Data Brief-Updated Release. Atlanta: National Center for Injury Prevention and Control Centers for Disease Control and Prevention; 2018.

2. Ministry of Gender Equality and Family of South Korea. The Final Report of 2016 Korean National Incidence Study. Seoul: Ministry of Gender Equality and Family of South Korea; 2016.

3. Ullman SE, Filipas HH. Predictors of PTSD symptom severity and social reactions in sexual assault victims. J Trauma Stress 2001;14:369-389.

4. Fischer S, Stojek M, Hartzell E. Effects of multiple forms of childhood abuse and adult sexual assault on current eating disorder symptoms. Eat Behav 2010;11:190-192.

5. Mason F, Lodrick Z. Psychological consequences of sexual assault. Best Pract Res Clin Obstet Gynaecol 2013;27:27-37.

6. Masters NT, Stappenbeck CA, Kaysen D, Kajumulo KF, Davis KC, George WH, et al. A person-centered approach to examining heterogeneity and subgroups among survivors of sexual assault. J Abnorm Psychol 2015;124:685-696.

7. Ullman SE, Relyea M, Peter-Hagene L, Vasquez AL. Trauma histories, substance use coping, PTSD, and problem substance use among sexual assault victims. Addict Behav 2013;38:2219-2223.

8. Davidson JR, Hughes DC, George LK, Blazer DG. The association of sexual assault and attempted suicide within the community. Arch Gen Psychiatry 1996;53:550-555.

9. Kim YS, Kim SJ, Kong BG, Kang JW, Moon JJ, Jeon DW, et al. Psychiatric symptoms among female adult victims of sexual molestation: comparison with rape victims. Korean J Psychosom Med 2016;24:208216.

10. Kim SH, Choi JY. The effect of post-traumatic cognition on the psychological sequelae of sexual violence in women. Health Soc Welfare Rev 2018;38:188-216.

11. Dworkin ER, Menon SV, Bystrynski J, Allen NE. Sexual assault victim- 
ization and psychopathology: A review and meta-analysis. Clin Psychol Rev 2017;56:65-81.

12. Peter-Hagene LC, Ullman SE. Sexual assault-characteristics effects on PTSD and psychosocial mediators: A cluster-analysis approach to sexual assault types. Psychol Trauma 2015;7:162-170.

13. Choi JH, Kim K, Kim JY. Profile of sexual assault experiences among the adult female: Analysis of the Nationwide Survey of Sexual Assault in Korea. Korean J Soc Welfare Stud 2019;50:271-296.

14. Macy RJ, Nurius PS, Norris J. Latent profiles among sexual assault survivors: Understanding survivors and their assault experiences. J Interpers Violence 2007;22:520-542.

15. French BH, Bi Y, Latimore TG, Klemp HR, Butler EE. Sexual victimization using latent class analysis: Exploring patterns and psycho-behavioral correlates. J Interpers Violence 2014;29:1111-1131.

16. Kim KH, Kim JW, Park HY, Ryou B. Profile of sexual violence experiences among the survivors using victim support services in Korea. Korean J Soc Welfare Stud 2016;47:255-280.

17. Jones JS, Rossman L, Wynn BN, Dunnuck C, Schwartz N. Comparative analysis of adult versus adolescent sexual assault: epidemiology and patterns of anogenital injury. Acad Emerg Med 2003;10:872-877.

18. Spohn CC. A comparison of sexual assault cases with child and adult victims. J Child Sex Abus 1995;3:59-78.

19. McCrae JS, Chapman MV, Christ SL. Profile of children investigated for sexual abuse: Association with psychopathology symptoms and services. Am J Orthopsychiatry 2006;76:468-481.

20. Campbell R, Raja S. The sexual assault and secondary victimization of female veterans: help-seeking experiences with military and civilian social systems. Psychol Women Q 2005;29:97-106.

21. Ullman SE. Psychometric characteristics of the Social Reactions Questionnaire: a measure of reactions to sexual assault victims. Psychol Women Q 2000;24:257-271.

22. Ullman SE. Relationship to perpetrator, disclosure, social reactions, and PTSD symptoms in child sexual abuse survivors. J Child Sex Abus 2007;16:19-36.

23. Ullman SE, Filipas HH, Townsend SM, Starzynski LL. The role of victim-offender relationship in women's sexual assault experiences. J Interpers Violence 2006;21:798-819.

24. Campbell R, Dworkin E, Cabral G. An ecological model of the impact of sexual assault on women's mental health. Trauma Violence Abuse 2009;10:225-246.

25. Ullman SE, Peter-Hagene L. Social reactions to sexual assault disclosure, coping, perceived control, and PTSD symptoms in sexual assault victims. J Community Psychol 2014;42:495-508.

26. Filipas HH, Ullman SE. Child sexual abuse, coping responses, selfblame, posttraumatic stress disorder, and adult sexual revictimization. J Interpers Violence 2006;21:652-672.

27. Ports KA, Ford DC, Merrick MT. Adverse childhood experiences and sexual victimization in adulthood. Child Abuse Negl 2016;51:313-322.

28. Kim KH, Ryou B, Kim JW. A Study of Development and Application on Korean Sexual Assault Case Record Abstraction Instrument (KSACRAI). Korean J Vict 2019;27:213-244.

29. Kim K, Mennen FE, Trickett PK. Patterns and correlates of co-occurrence among multiple types of child maltreatment. Child Fam Soc Work 2017;22:492-502.

30. Cicchetti D. Defining Child Maltreatment: The Interface between Policy and Research. In: Cicchetti D, Editor Child Abuse, Child Development, and Social Policy. Norwood, NJ: Ablex; 1993.

31. Sim KS, Ahn HN. A Validation of the Korean Version of the Social Reactions Questionnaire. Korean J Couns Psychother 2014;26:271-296.

32. Felitti VJ. The relationship of adult health status to childhood abuse and household dysfunction. Am J Prev Med 1998;14:245-258.

33. Dong M, Giles WH, Felitti VJ, Dube SR, Williams JE, Chapman DP, et al. Insights into causal pathways for ischemic heart disease: adverse childhood experiences study. Circulation 2004;110:1761-1766.

34. Edwards VJ, Holden GW, Felitti VJ, Anda RF. Relationship between multiple forms of childhood maltreatment and adult mental health in community respondents: results from the adverse childhood experiences study. Am J Psychiatry 2003;160:1453-1460.

35. Hughes K, Bellis MA, Hardcastle KA, Sethi D, Butchart A, Mikton C, et al. The effect of multiple adverse childhood experiences on health: a systematic review and meta-analysis. Lancet Public Health 2017;2:e356e366.

36. Felitti V, Anda R. The Relationship of Adverse Childhood Experiences to Adult Medical Disease, Psychiatric Disorders and Sexual Behavior: Implications for Healthcare. In: Lanius R,Vermetten E, Pain C, Editors. The Impact of Early Life Trauma on Health and Disease: The Hidden Epidemic. Cambridge: Cambridge University, 2010, p.77-87.

37. Foa EB, McLean CP, Zang Y, Zhong J, Powers MB, Kauffman BY, et al. Psychometric properties of the Posttraumatic Diagnostic Scale for DSM-5 (PDS-5). Psychol Assess 2016;28:1166-1171.

38. Radloff LS. The CES-D scale: a self-report depression scale for research in the general population. Appl Psychol Meas 1977;1:385-401.

39. Chon KK, Choi SC, Yang BC. Integrated Adaptation CES-D in Korea. Korean J Psychol Health 2001;6:59-76.

40. Weissman MM, Sholomskas D, Pottenger M, Prusoff BA, Locke BZ. Assessing depressive symptoms in five psychiatric populations: a validation study. Am J Epidemiol 1977;106:203-214.

41. Beck AT, Epstein N, Brown G, Steer RA. An inventory for measuring clinical anxiety: psychometric properties. J Consult Clin Psychol 1988; 56:893-897.

42. Beck AT, Steer RA. Relationship between the Beck anxiety inventory and the Hamilton anxiety rating scale with anxious outpatients. J Anxiety Disord 1991;5:213-223.

43. Kwon SM. Assessment of psychopathology in anxiety disorder. Korean J Physiol Pharmacol 1997;6:37-51.

44. Carlson EB, Putnam FW. An update on the dissociative experiences scale. Dissociation Progress Dissociative Disorder 1993;6:16-27.

45. Kim D, Im H, Roh S. Factor structure of Korean dissociative experience scale (KDES-II) among psychiatric patients. J Korean Neuropsychiatr Assoc 2007;46:136-143.

46. Ewing JA, Rouse BA. Identifying the hidden alcoholic. 29th International Congress on Alcohol and Drug Dependence. Sydney, Australia; 1970.

47. Dhalla S, Kopec JA. The CAGE questionnaire for alcohol misuse: a review of reliability and validity studies. Clin Invest Med 2007;30:33-41.

48. Harkness AR, McNulty JL, Ben-Porath YS. The Personality Psychopathology Five (PSY-5): Constructs and MMPI-2 scales. Psychol Assess 1995; 7:104-114.

49. Cotton MA, Ball C, Robinson P. Four simple questions can help screen for eating disorders. J Gen Intern Med 2003;18:53-56.

50. Posner K, Brown GK, Stanley B, Brent DA, Yershova KV, Oquendo MA, et al. The Columbia-Suicide Severity Rating Scale: initial validity and internal consistency findings from three multisite studies with adolescents and adults. Am J Psychiatry 2011;168:1266-1277.

51. Interian A, Chesin M, Kline A, Miller R, St. Hill L, Latorre M, et al. Use of the Columbia-Suicide Severity Rating Scale (C-SSRS) to classify suicidal behaviors. Arch Suicide Res 2018;22:278-294.

52. Pai D, Woo JM, Son MH, Lee C. The reliability and validity of the Korean version of Columbia-Suicide Severity Rating Scale in alcohol dependent patients. Psychiatry Investig 2015;54:222-227.

53. Freund R, Littell R. SAS System for Regression. 3rd Edition. Cary, NC: SAS Inst:; 2000.

54. Trickett PK, Noll JG, Reiffman A, Putnam FW. Variants of intrafamilial sexual abuse experience: Implications for short-and long-term development. Dev Psychopathol 2001;13:1001-1019.

55. Ahrens CE. Being silenced: the impact of negative social reactions on the disclosure of rape. Am J Community Psychol 2006;38:31-34.

56. Campbell R. The community response to rape: Victims' experiences with the legal, medical, and mental health systems. Am J Community Psychol 1998;26:355-379. 
57. Campbell R, Raja S. Secondary victimization of rape victims: insights from mental health professionals who treat survivors of violence. Violence Vict 1999;14:261-275.
58. Elklit A, Christiansen DM. Risk factors for posttraumatic stress disorder in female help-seeking victims of sexual assault. Violence Vict 2013;28: 552-568. 